\title{
A COOPERAÇÃO SUL-SUL DO BRASIL COM A ÁFRICA
}

\author{
INTRODUÇÃO
}

\author{
Enara Echart Muñoz ${ }^{*}$
}

Nos últimos tempos, assistimos a uma "ascensão do Sul”1 no cenário internacional, reforçando as relações Sul-Sul, dentre as quais se destaca a cooperação para o desenvolvimento em um mundo ainda altamente desigual. $\mathrm{O}$ Brasil teve um protagonismo especial nessa área, defendendo um sistema internacional de cooperação mais diverso em termos de princípios, modelos e práticas, derivado da própria existência de diferentes experiências históricas e posições sistêmicas. A solidariedade, a ausência de condicionalidades, a horizontalidade e o respeito à soberania são alguns dos princípios reclamados por essa nova forma de cooperação.

A Cooperação Sul-Sul (CSS) se apresenta como uma forma de apoio ao desenvolvimento, de criação ou fortalecimento de laços políticos, econômicos ou culturais, de negociação quanto a um maior protagonismo internacional e ainda como uma fonte de soft power e de credibilidade no cenário global. As modalidades que essa cooperação adota são variadas

* Universidade Federal do Estado do Rio de Janeiro (UNIRIO). Escola de Ciência Política - CCJP / UNIRIO.

Rua Voluntários da Pátria, 107. Cep: 22270-000. Botafogo Rio de Janeiro - Brasil. enara.munoz@unirio.br

${ }^{1}$ Título do Relatório de Desenvolvimento Humano do Programa de Nações Unidas para o Desenvolvimento de 2013. Disponível em http://hdr.undp.org/es/content/informe-sobre-desarrollo-humano-2013 (cooperação técnica, ajuda humanitária, contribuições a fundos multilaterais, operações de paz, etc.). Além da dimensão bilateral, está ganhando peso a cooperação trilateral, com a parceria entre diversos países do Sul, do Norte (Estados Unidos, Japão, Inglaterra, etc.), e organismos internacionais (Programa Mundial de Alimentos, Organização das Nações Unidas para a Alimentação, entre outros).

Os principais setores nos quais está mais presente a atuação brasileira na CSS são: agricultura, saúde e educação (além de defesa). Os artigos que compõem este dossiê estão centrados, prioritariamente, na análise desses setores. Nessas áreas, o Brasil acumulou experiências que deram importantes resultados no âmbito doméstico, as quais se tornaram referências internacionais e podem ser compartilhadas e aplicadas em países com problemas semelhantes de desenvolvimento. É o caso do Programa de Aquisição de Alimentos-África, da experiência com os medicamentos antirretrovirais ou da formação e educação, entre outros. Essa expertise outorga certa credibilidade quando apresentada internacionalmente.

Para desenvolver os projetos de cooperação internacional, além da própria Agência Brasileira de Cooperação (ABC), grande núme- 
ro de atores domésticos são mobilizados e envolvidos, direta ou indiretamente, nas negociações e na implementação, sejam eles públicos - Ministério de Desenvolvimento Social, Ministério do Desenvolvimento Agrário, Ministério do Desenvolvimento, Indústria e Comercio Exterior, Banco Nacional de Desenvolvimento Econômico e Social, Empresa Brasileira de Pesquisa Agropecuária, etc. - ou privados, desde empresas que, de alguma maneira, podem ser beneficiadas pela atuação brasileira em alguns setores, até movimentos sociais surgidos em protesto contra alguns dos efeitos negativos que os projetos de desenvolvimento têm em termos sociais ou ambientais. Assim, para além dos governos (principais atores da CSS), empresas e movimentos sociais disputam os sentidos e interesses situados por trás dessas práticas.

De fato, as análises dos projetos da cooperação brasileira com países africanos examinados nos artigos que compõem este dossiê demonstram importantes tensões e contradições que vão além da definição estrita da CSS, podendo ser conceituais ou de coerência política. No caso da alimentação, por exemplo, há grandes diferenças entre aqueles que defendem que se trata de um direito e os que vêm os alimentos como uma mercadoria. Analisar projetos nessa área exige levar em conta as eventuais incoerências que as diversas políticas produzem nos processos de desenvolvimento dos países parceiros. A incoerência é entendida não só como uma dessintonia entre ค o discurso e a prática, mas também é derivada da falta de coordenação e complementaridade entre as ações dos diversos atores, ou da consistência dos projetos em longo prazo.

Essas são algumas das limitações encontradas no desenho de uma política pública de ¿ cooperação internacional no Brasil, preocupação \& que também está presente nos artigos aqui apre今ิ sentados. O grande número de atores envolvidos $\therefore$ implica uma diversidade de práticas, as quais dificultam a coordenação institucional e podem colocar em risco a coerência da política. Por outro lado, as tensões entre o público e o privado que envolvem essa política terminam gerando contradições entre o discurso e a prática e entre as diversas práticas. Um problema adicional é a forte exclusão dos atores da sociedade civil, que reivindicam maior participação em uma política pública que se quer democrática.

Essas questões são estudadas em uma área geográfica determinada, a África, pela importância que esse continente ganhou na CSS brasileira. Tanto as relações entre Brasil e África quanto as práticas de CSS, apesar de não serem novas, ganham impulso no início de século XXI, principalmente com o governo de Lula da Silva. O continente africano, receptor tradicional da ajuda ao desenvolvimento dos países do Norte, tornou-se um parceiro importante nessa reconfiguração da CSS, recebendo, por exemplo, mais de $45 \%$ dos desembolsos do Fundo IBAS (Índia, Brasil e África do Sul), e quase o $40 \%$ da cooperação técnica brasileira. ${ }^{2}$ Dentre os países africanos que mais fundos recebem estão os Países Africanos de Língua Oficial Portuguesa (PALOP), devido a razões históricas e institucionais, com destaque para Moçambique, que serve de estudo de caso em muitos dos artigos deste dossiê, por ser destino de importantes projetos estruturantes.

Os países africanos não são aqui tratados como receptores passivos da cooperação, e sim como parceiros cuja capacidade de agência é tida em conta quando se analisam os efeitos dos projetos apresentados. Um tema recorrente nos artigos é a necessidade de apropriação dos projetos de desenvolvimento. Independentemente de boas intenções e de semelhanças históricas, é necessário ajustar a cooperação às realidades locais nas quais se trabalha. Longe da ideia defendida por alguns de que haveria sempre uma solução brasileira para os problemas africanos, trata-se de evitar impor modelos exógenos, e sim de adaptá-los às demandas do parceiro, com práticas reais, de reciprocidade, de troca de experiências, de viagens de ida e volta. O caso da educação é paradigmático: os materiais pedagógicos precisam ser adaptados às necessidades curriculares locais (e não exportados do Brasil para Moçambique). Da mesma forma, o próprio ensino sobre a África no Brasil pode ser enriquecido com a experiência

2 Segundo dados do Fundo IBAS (http://tcdc2.undp.org/ ibsa/) e da Agência Brasileira de Cooperação (http://www. abc.gov.br). 
dos professores africanos. É importante chamar a atenção sobre os problemas indesejados que podem aparecer se a cooperação não for avaliada e adequada ao contexto, como o perigo assinalado em artigo deste dossiê de enfraquecimento do sistema público de saúde quando o objetivo era justamente o contrário. Para além da apropriação, é interessante notar como os países desenvolvem inclusive estratégias de "extraversão"3 para administrar e aproveitar essa cooperação de forma diferente da idealizada originalmente (no caso da fábrica de retrovirais, por exemplo) a fim de fortalecer sua própria posição interna ou a de sua elite.

A cooperação internacional é a temática e a área de pesquisa dos autores do presente dossiê, os quais colaboram entre si em diversas redes $^{4}$ e projetos, ${ }^{5}$ como espaços de troca de ideias e aprofundamento das reflexões, o que permitiu chegar ao conjunto de artigos aqui reunidos. As relações entre o Brasil e a África servem de fio condutor para uma reflexão que vai além do debate teórico, já que é enriquecida com experiências práticas derivadas de pesquisas de campo, essenciais para melhorar o conhecimento e aproximar as duas realidades. A partir de premissas e inquietações comuns, os artigos exploram, por meio de estudos de caso, os principais projetos da cooperação brasileira na África, com destaque para projetos estruturantes, voltados para o fortalecimento de setores estratégicos.

O primeiro artigo, de Carlos R. S. Milani, Francisco Carlos da Conceição e Timóteo Saba M'Bunde, apresenta-nos o panorama da CSS brasileira quanto a recursos, modalidades, estrutura organizacional e setorial, etc., para analisar, de forma mais concreta, a cooperação em educação nos Países Africanos de Língua

\footnotetext{
${ }^{3}$ Definidas por Jean-François Bayart em África en el espejo. Colonialidad, criminalidad y Estado. México: Fondo de Cultura Económica, 2011.

${ }^{4}$ Entre elas o Grupo de Trabalho sobre Cooperação Sul-Sul e Políticas de Desenvolvimento na América Latina do Conselho Latino-Americano de Ciências Sociais / CLACSO.

${ }^{5}$ Como a publicação do Atlas da Política Externa Brasileira, EdUERJ/CLACSO, ou as pesquisas sobre A cooperação SulSul brasileira com Moçambique, Guiné-Bissau e Senegal: discursos, práticas e percepções no campo da alimentação e A cooperação brasileira para o desenvolvimento internacional com Ảngola e Moçambique: entre o discurso solidário e a prática pragmática, ambas financiadas, pelo CNPQ.
}

Oficial Portuguesa (PALOP), que recebem a maioria dos projetos CSS do Brasil na África, e mais concretamente em Moçambique, dando especial atenção às percepções dos parceiros dessa cooperação.

O segundo artigo, de Enara Echart Muñoz e Tassia Carvalho, analisa outro setor importante da cooperação brasileira, a alimentação, que é, ao mesmo tempo, uma área-chave para as empresas brasileiras. As tensões e disputas geradas entre os diversos atores envolvidos e sua visão da alimentação, ou como direito que deve ser garantido, ou como mercadoria que pode gerar importantes lucros, são analisadas a partir de um enfoque de coerência de políticas com o desenvolvimento.

No terceiro artigo, de Elga Lessa de Almeida, também há uma preocupação com a coerência entre o discurso solidário e a ação pragmática da cooperação brasileira em Moçambique, com uma análise de dois projetos emblemáticos: a implantação da fábrica de medicamentos antirretrovirais e o Programa de Cooperação Tripartida para o Desenvolvimento Agrícola da Savana Tropical em Moçambique (ProSavana). A ambivalência entre os diferentes interesses imbricados de diversas formas se mostra claramente em ambos os projetos.

A interface entre as políticas públicas e os interesses privados é o foco do quarto artigo, de Ana Garcia e Karina Kato, que se dedica a analisar a participação do setor empresarial na cooperação brasileira em Moçambique. O caso do corredor logístico de Nacala é um exemplo claro da interseção entre cooperação, investimento e financiamento na África, em consonância, inclusive, com as políticas defendidas nos organismos financeiros internacionais, como o Banco Mundial.

O último artigo, de Andre Luis Nascimento dos Santos, Marcos Fábio Rezende Correia e Paulo Victor de Oliveira, aborda um tema pouco estudado no âmbito da Cooperação Sul-Sul, analisando as idas e vindas das relações entre o Brasil e a África a partir de atores, temáticas e narrativas que costumam estar invisibilizados. As redes de solidariedade criadas por atores religiosos - nesse caso, os iorubanos - e suas trocas simbólicas outorgam um novo significado 
ao campo da cooperação transnacional.

Finalmente, o dossiê se propõe a analisar as narrativas oficiais à luz de pesquisas empíricas, adotando sempre uma visão sistêmica que apresente o quadro complexo das relações entre o Brasil e os países africanos, nas quais se imbricam diversos atores, interesses e práticas. A posição do Brasil como global player, observada pela ótica da cooperação internacional, tem repercussões políticas e econômicas, inclusive na expansão internacional de empresas brasileiras que recebem apoio de políticas públicas, demostrando uma forte complementaridade entre cooperação, financiamento e investimentos.

A definição e a implementação de projetos de cooperação internacional, como parte da política externa brasileira, também levaram a um incremento de participação de atores há tempos envolvidos em redes transnacionais de solidariedade, mas invisibilizados no campo da CSS: os movimentos sociais e as redes religiosas. Os projetos de cooperação, muitas vezes, geram impactos no território, o que muda a própria forma de vida de muitas comunidades. A participação dessas comunidades na hora de negociar os conflitos derivados das consequências sociais e ambientais dos projetos, assim como do processo crescente de "estrangeirização" da terra a que estão submetidas, é uma demanda importante nas agendas atuais de cooperação. Também o caso das redes de matriz iorubana mostra uma visão "multilocal", ou "translocal" de ida e volta, ressaltando $\stackrel{\text { : }}{*}$ as profundas origens das relações entre o Brasil e a África, que vão além de high ou low politics, para adentrar o terreno da deep politics. transnacional. Ciências Sociais Unisinos, v. 46, p. 28-35, 2010. funda de relacionamento, que vem de baixo e de dentro de uma memória comum. Aproxima-se do que os xhosa denominam ubuntu, uma filosofia que entende que $\mathrm{Eu}$ sou porque nós somos: a nossa historia e o nosso futuro são compartilhados, e devemos trabalhar conjuntamente para melhora-los. Desmond Tutu, Prêmio Nobel da Paz, a explicava assim: "Uma pessoa com Ubuntu está aberta e disponível para as outras, apoia as outras, não se sente ameaçada quando outras pessoas são capazes e boas, com base em uma autoconfiança que vem do conhecimento de que ele ou ela pertence a algo maior, que é diminuído quando outras pessoas são humilhadas ou diminuídas, quando são torturadas ou oprimidas" (p. 35). ${ }^{6}$

Queremos, aqui, recuperar essa visão de uma África contemporânea com incrível capacidade de adaptação, de resiliência, que nos permita superar a visão negativa, passiva, associada ao continente: os africanos são atores em sua própria história, sempre dispostos a converter os freios externos em alguma criação nova. É isso também o que acontece na sua relação com o Brasil. Aprender a olhar essa relação com novas lentes, diferentes daquelas proporcionadas pela tradicional cooperação Norte-Sul, nos ensina a decifrar discursos excludentes em relação ao outro, inclusive quando esse outro faz parte de nós. Mostra-nos o que significa realmente ter experiências comuns, a partir de uma identidade compartilhada, e quais são os perigos a superar e as possibilidades de solidariedade e de cooperação construídas sobre essas bases.

Recebido para publicação em 10 de dezembro de 2015 Aceito em 20 de dezembro de 2015

Enara Echart Muñoz - Doutora em Direito Internacional Público e Relações Internacionais. Professora da Universidade Federal do Estado do Rio de Janeiro (UNIRIO), onde coordena o GRISUL (Grupo de Relações Internacionais e Sul Global). Pesquisadora do LABMUNDO (IESP-UERJ) e do Instituto Universitario de Desarrollo y Cooperación da Universidad Complutense de Madri. Seus principais âmbitos de atuação são Relações Internacionais; Cooperação para o Desenvolvimento; Direitos Humanos; Movimentos Sociais e Sociedade Civil, Migrações e Desenvolvimento, África, América Latina. Publicações recentes: Cooperación Sur-Sur y derechos humanos: el derecho a la alimentación en la cooperación brasileña y argentina. Revista Española de Desarrollo y Cooperación, v. 32, p. 98-117, 2013; Does the South challenge the Geopolitics of International Development Cooperation?. Geopolitica(s): revista de estudios sobre espacio y poder, v. 4-1, p. 35-41, 2013; Dez anos de Seattle, o movimento antiglobalização e a ação coletiva

${ }^{6}$ No seu livro: No Future Without Forgiveness. New York: Doubleday, 1999. 